\title{
Evaluasi Animasi 3d Legenda Tarian Sabuk Janur Dengan Metode Rigging Bone
}

\author{
Fendi Aji Purnomo \\ Fakultas MIPA, Program Studi D3 Teknik Informatika \\ Universitas Sebelas Maret \\ Email: fendi_aji@mipa.uns.ac.id \\ Firma Sahrul Bahtiar, Ahzan Miftahudin Zuhri, Afwan Amirul Muchsinin \\ Program Studi D3 Teknik Informatika \\ Universitas Sebelas Maret
}

Info Artikel

\section{Kata Kunci :}

Kebudayaan, Legenda Tarian Sabuk Janur, Animasi 3D

\section{Keywords :}

Culture, Legend of Tarian Sabuk Janur, 3D Animation

\section{Tanggal Artikel}

Dikirim : 25 Oktober 2018

Direvisi : 15 November 2018

Diterima : 20 November 2018

\begin{abstract}
Abstrak
Indonesia dewasa ini, budaya pada masyarakat mulai mendapat pengaruh dari budaya asing sehingga budaya yang merupakan peninggalan dari leluhur bangsa mulai terkikis. Salah satunya adalah kebudayaan berupa cerita legenda yang berkembang di daerah masing - masing, sehingga menjadi ironis ketika anak zaman sekarang tidak mengetahui bahkan tidak peduli akan budayanya sendiri. Salah satu cerita legenda yang berkembang yaitu "Tarian Sabuk Janur" yang berasal dari daerah Girimulyo, Karanganyar yang kental menceritakan tentang kearifan dan keramahan budaya. Media edukasi yang saat ini digemari oleh masyarakat umum salah satunya adalah film animasi. Film animasi "Legenda Tarian Sabuk Janur" dibuat dengan metode 3 Dimensi, yang memiliki durasi waktu 6 menit 27 detik, dengan spesifikasi ekstensi .mp4, resolusi video 1280x720, dan frame rate $24 \mathrm{fps}$. Dalam pembuatan film tersebut, menggunakan software Blender Animation Studio. Berdasarkan pengkajian kuisioner yang telah dilakukan, dapat diketahui bahwa $82 \%$ responden dapat memahami isi cerita film animasi 3D Legenda Tarian Sabuk Janur. Dan film disajikan dengan baik rata-rata dengan prosentase sebesar $75 \%$.
\end{abstract}

Abstarct

Indonesia today, culture in the community began to get the influence of foreign culture so that the culture is a relic of the nation's ancestors began to erode. One of them is the culture of a legend story that developed in their respective regions, so it becomes ironic when children today do not know even care about their own culture. One of the growing legends of the story is "Tarian Sabuk Janur" which comes from Girimulyo region, Karanganyar is thick telling about wisdom and cultural friendliness. Media education currently popular by the public one of them is the animated film. The animated film " The Legend of Tarian Sabuk Janur " was made with the 3 Dimensional method, which has a duration of 6 minutes 27 second, with extension specification .mp4, 1280x720 video resolution, and frame rate of $24 \mathrm{fps}$. In the making of the film, using Blender Animation Studio software. Based on the questionnaire review, $82 \%$ of respondents can understand the contents of the 3D animated story of Janur Belt Dance Legend. And the film is well presented on average with a percentage of $75 \%$. 


\section{PENDAHULUAN}

Budaya memiliki kaitan erat dengan masyarakat di dalamnya, sehingga periaku masyarakat pada suatu tempat dapat dipengaruhi oleh budaya yang ada dalam masyarakat tersebut. Namun sebaliknya, budaya dapat dipengaruhi juga oleh perilaku masyarakat sehingga dapat terkikis atau terpengaruh oleh budaya lainnya. Seperti yang terjadi di Indonesia dewasa ini, budaya pada masyarakat mulai mendapat pengaruh dari budaya asing sehingga budaya yang merupakan peninggalan dari leluhur bangsa mulai terkikis.

Salah satu contoh budaya yang mulai terkikis adalah Tarian daerah. Tarian daerah dapat memiliki filosofi, cerita maupun nilai-nilai luhur didalamnya. Pada zaman modern ini, masyarakat mulai kurang peduli dengan tarian daerah, bahkan mulai tidak peduli pada tarian daerah yang merupakan bukti nyata peninggalan leluhur. Contoh nyata tarian daerah yang mulai kurang terkikis adalah Tarian Sabuk Janur, Tarian Sabuk Janur merupakan tarian yang berasal dari daerah Girimulyo, Karanganyar. Tarian Sabuk Janur memiliki filosofi yang sangat kuat dalam lingkaran histori, namun tarian ini kurang begitu dikenal oleh masyarakat jaman sekarang atau yang sering disebut kaum millenial.

Masyarakat millenial kini lebih tertarik pada hiburan yang tercipta melalui perkembangan teknologi, salah satu diantaranya adalah animasi. Animasi merupakan salah satu produk dari teknologi yang ada saat ini yang dalam pemanfaatannya digunakan dalam berbagai bidang, mulai dari sekedar hiburan, edukasi, sosial, hingga dalam pelestarian budaya. Telah banyak pengambangan film animasi baik 2D maupun 3D untuk tujuan edukasi kepada masyarakat. Beberapa Produk animasi dalam model 2D telah dikembangkan seperti pengenalan cerita rakyat Legenda Batu Kuwung [1], Legenda Gunung Tugel [2]. Sementara pengembangan film animasi 3D seperti cerita Batu Belah BAtu Betangkup [3], Legenda Danu Toba [4], Legenda Toar Lumimuut [5], dan Legenda Baru Klinting [6]. Metode pengembangan film animasi telah dikembangkan dengan teknik cinematografi [3], teknik video grafis [1], dan teknik model 3D [4][5][6]. Dalam penelitian ini akan mengambangan film animasi 3D menggunakan teknik rigging Bone yaitu dengan memberikan animasi dibantu dengan bone yang diberikan pada model 3D tersebut kemudian dianimasikan dengan memberikan prinsip-prinsip animasi pada gerakan yang dilakukan.

\section{METODOLOGI PENELITIAN}

Tahap pembuatan film animasi dilakukan dalam 3 tahap yaitu pra produksi, produksi dan pasca produksi. Pra Produksi merupakan tahap persiapan yang dilakukan sebelum tahap produksi dimulai. Tahap ini dimulai dari penentuan konsep dan tema yang kemudian dikembangkan menjadi storyline hingga pembuatan story board. Ide dan tema dalam film adalah patokan awal untuk memulai produksi. Ide dari film animasi ini bersumber dari Tarian Sabuk Janur, sebuah tarian yang berasal dari daerah Grimulyo, Karanganyar. Tarian Sabuk Janur memiliki cerita dan filosofi yang sangat kuat dan erat kaitannya dengan legenda daerah tersebut. "Sabuk Janur" sendiri diambil dari sebuah "sabuk" atau ikat pinggang yang terbuat dari sebuah daun kelapa atau disebut "Janur". Setelah ide dan tema kemudian dikembangkan menjadi sebuah cerita dan skenario yang kemudian dapat diwujudkan dalam bentuk storyline. Tahapan selanjutnya adalah pembuatan storyboard yang diwujudkan dalam bentuk urutan gambar. Tahapan selanjutnya dibuat visual storyboard terdiri dari storyboard dan audio dubbing sehingga menjelaskan alur cerita.

Tahap produksi, terdapat tahapan antara lain modelling yang meliputi karakter, environment, dan aset-aset pendukung lainnya. Pada tahap modelling karakterdigunakan blueprint sebagai acuan bentuk karakter dan sculpting sebagai agar karakter bisa lebih detail. Material dan Texturing, baik karakter, environment, maupun aset-aset pendukung menggunakan material dan antic . Rigging, merupakan tahap pemberian tulang pada objek-objek 3D agar nantinya bisa digerakkan atau dianimasikan pada sumbu $x, y$, maupun z. Animate, dengan menggerakkan bone atau tulang pada setiap objek sesuai gerakan-gerakan yang dimaksud pada storyboard. Pada tahap anímate, memperhatikan 12 prinsip animasi. Audio Producing dan Recording, audio yang digunakan sebagai audio narasi diperoleh dari Recording atau Dubbing, sedangkan audio yang digunakan sebagai Background music diperoleh dari Audio Produksi.

Tahap pasca produksi, yaitu berupa editing. Merupakan proses merangkai/merekonstruksi kembali scene yang terpisah menjadi satu kesatuan sehingga enak dipandang atau dapat diartikan juga sebagai proses penggabungan berbagai elemen seperti video, image serta audio menjadi satu kesatuan yang utuh. Tahap compositing, compositing yang kompleks, merupakan aspek yang cukup sulit dalam proses digital imaging untuk dikuasai. Sebelum melakukan compositing, bagianbagian yang digabung harus dirender terlebih dahulu untuk kemudian digabungkan kembali.

\section{HASIL DAN PEMBAHASAN}

Tarian Sabuk Janur merupakan sebuah tarian yang berasal dari daerah Grimulyo, Karanganyar. Tarian Sabuk Janur memilki cerita dan filosofi yang sangat kuat dan erat kaitannya dengan legenda daerah tersebut. "Sabuk Janur" sendiri diambil dari sebuah "sabuk" atau ikat pinggang yang terbuat dari sebuah daun kelapa atau disebut "Janur". 
Dalam tarian ini mengandung cerita yaitu tokoh seorang pengembara dan juga senopati yang bernama Ki Sabuk Janur. Ki Sabuk Janur dalam cerita ini mendapat tugas untuk mengalirkan air dari pegunungan agar sampai ke desa Balaikambang, karena di desa tersebut sedang mengalami kekeringan. Dalam perjalanan Ki Sabuk Janur, dia dihadapkan dengan seekor Kelabang raksasa atau disebut "Kiongkong". Kiongkong yang awalnya menjadi musuh dan bertarung dengan Ki Sabuk Janur, pada akhirnya membantunya untuk memindahkan batu besar yang menjadi penghalang air sampai ke desa.

Model karakter yang disajikan yaitu Ki Sabuk Janur, Nyai Gadung Melati, Kiongkong (kelabang raksasa). Ki Sabuk Janur merupakan tokoh laki-laki dalam cerita ini. Tokoh ini digambarkan sebagai laki-laki dewasa dengan pakian serba hitam dikombinasikan dengan sarung batik pada celana dan memakai blangkon. Tokoh ini digamarkan sebagai tokoh yang gagah, sakti, dan baik hati. Ki Sabuk Janur merupakan tokoh utama dalam cerita ini disajikan pada Gambar 1. Nyai Gadung Melati merupakan tokoh perempuan dalam cerita ini. Tokoh ini digambarkan sebagai perempuan dewasa dengan pakaian adat Jawa Tengah. Tokoh ini digambarkan sebagai tokoh yang cantic rupawan dan lemah lembut. Nyai Gadung Melati seperti ditunjukkan Gambar 2, merupakan tokoh yang dijadikan imbalan sayembara dalam mengatasi kekeringan. Kiongkong merupakan tokoh dalam cerita yang digambarkan sebagai kelabang raksasa yang menakutkan dengan warna tubuh putih kemerahan. Tokoh ini merupakan tokoh monster yang kejam dan ditunjukkan pada Gambar 3.

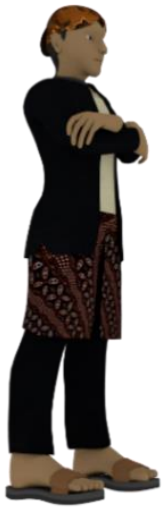

Gambar 1. Ki Sabuk Janur

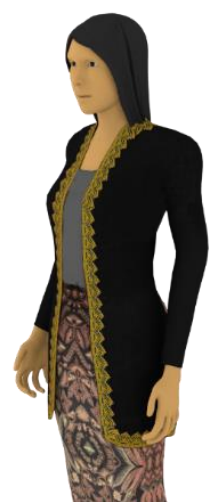

Gambar 2. Nyai Gadung Mlati

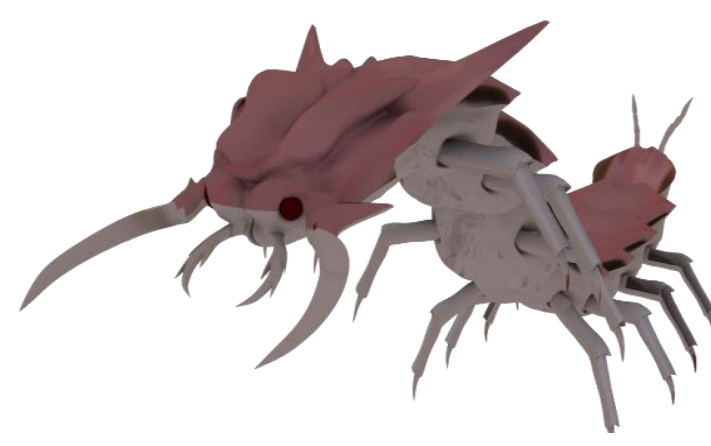

Gambar 3. Kiongkong (Kelabang Raksasa)

Pembuatan storyboard dimaksudkan sebagai acuan dalam pembuatan animasi cerita "Legenda Tarian Sabuk Janur". Storyboard menggambarkan kondisi dari setiap scene, yaitu meliputi tokoh karakter, konsep kamera, property yang digunakan, backsound, hingga Panjang waktu dari setiap scene tersebut. Tabel 1 adalah storyboard dari cerita "Legenda Tarian Sabuk Janur".

Tabel 1. Storyboard

\begin{tabular}{|c|c|c|c|}
\hline Scene & Ilustrasi & Waktu & Keterangan \\
\hline 1 & & $00.11-00.15$ & $\begin{array}{l}\text { 1. Opening kamera panning pada } \\
\text { environment } \\
\text { 2. Musik backsound khas } \\
\text { opening film }\end{array}$ \\
\hline 2 & & $00.16-00.45$ & $\begin{array}{l}\text { 1. kamera bergerak menunjukan } \\
\text { suasana subur desa } \\
\text { balaikambang } \\
\text { 2. suasana berubah menjadi } \\
\text { kekeringan }\end{array}$ \\
\hline
\end{tabular}



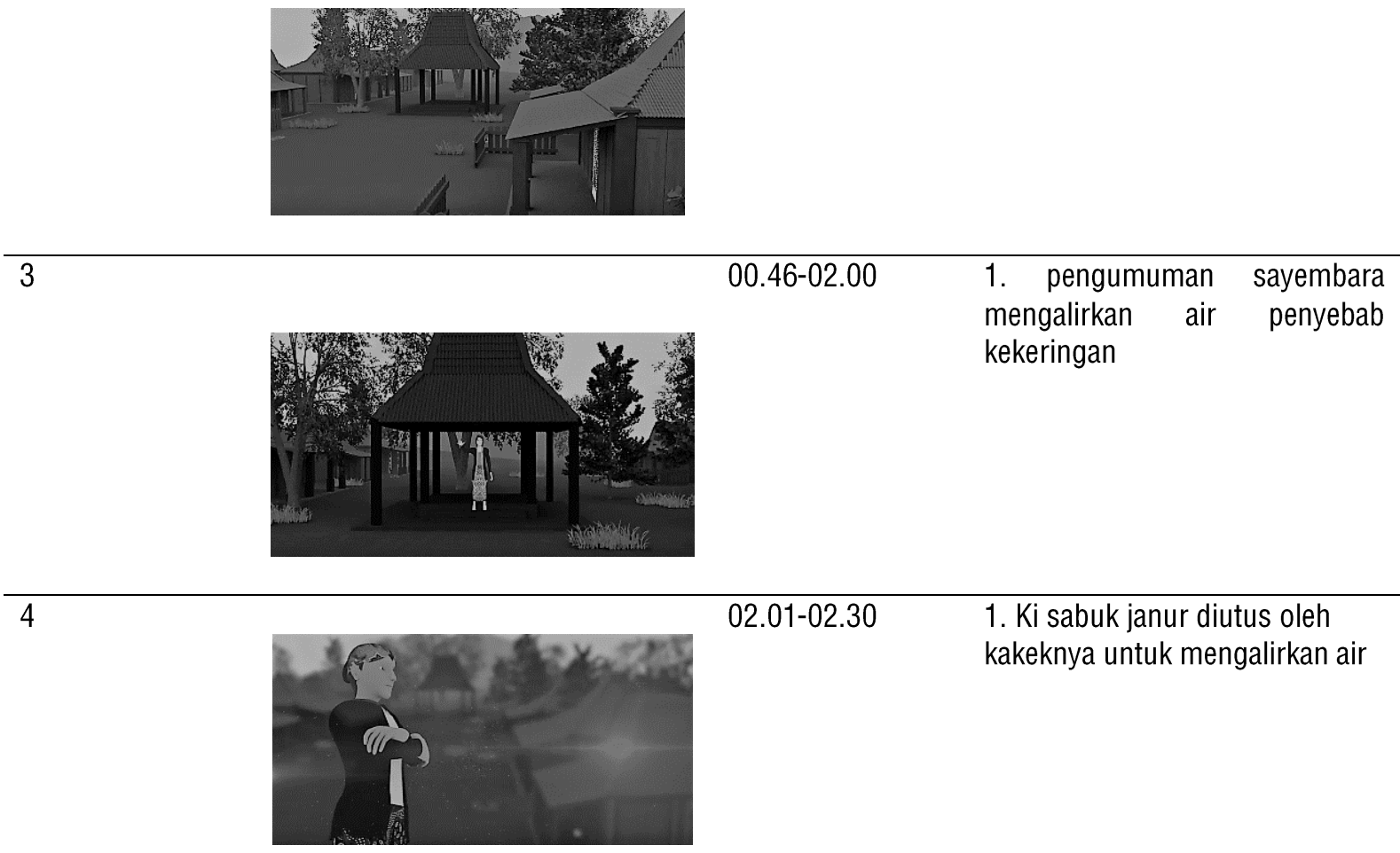

\begin{tabular}{lll}
\hline 5 & $02.31-03.00$ & $\begin{array}{l}\text { 1. ki sabuk janur berjalan } \\
\text { menuju pegunungan untuk } \\
\text { mencari sumber kekeringan }\end{array}$ \\
\hline 6 & $03.01-03.30$ & $\begin{array}{l}\text { 1. background music tenang } \\
\text { 2. ki sabuk janur beristirahat di } \\
\text { padang rumput yang luas } \\
\text { 3. background music berubah } \\
\text { tempo menjadi cepat }\end{array}$ \\
4. ki sabuk janur bertemu \\
kiongkong (kelabang raksasa)
\end{tabular}




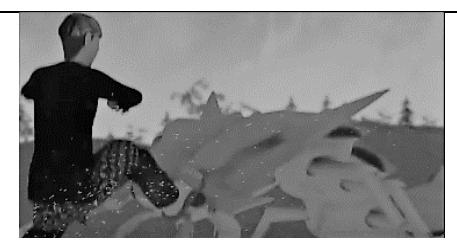

8

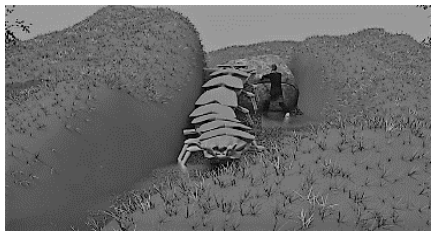

04.01-04.30

1. background music mulai

pelan

2. kiongkong kalah dari ki sabuk

janur

3. kiongkong membantu ki

sabuk janur mengalirkan sumber

air

Dalam Cerita "Legenda Tarian Sabuk Janur" terdapat 3 tokoh dan 1 narator. Diantaranya Ki Sabuk Janur, Nyai Gadung melati, dan kiongkong (kelabang raksasa). Adapun pengisi suara dari tokoh-tokoh tersebut adalah narrator yaitu Ahzan Miftahudin Zuhri, Ki Sabuk Janur oleh Afwan Amirul Muchsinin, Nyai Gadung Melati oleh Nabila Ardhiana, dan Kiongkong oleh Ahzan Miftahudin Zuhri.

Proses rendering pada film animasi 3 Dimensi legenda Tarian Sabuk Janur dipisah menurut masing - masing bagian scene agar tidak memberatkan computer. Proses rendering ini langsung menggunakan software Blender Animation Studio dan belum termasuk efek - efek video didalamnya. Pemberian visual efek dilakukan dengan software after effect. Berikut adalah pengaturan output yang digunakan pada proses rendering film animasi 3 Dimensi legenda Tarian Sabuk Janur yaitu resolusi video $1280 \times 720$ px, frame rate 24fps, format output MP4 dengan encoding H.264-AAC. Setelah film animasi selesai dibuat tahap selanjutnya yaitu disampaikan kepada masyarakat mengenai kemanfaatan film animasi tersebut. Gambar 4, telah dilakukan sosialisasi produk kepada masyarakat Karangpandan di Telaga Madirda, tanggal 8 Agustus 2018 yaitu tempat legenda tersebut terjadi.

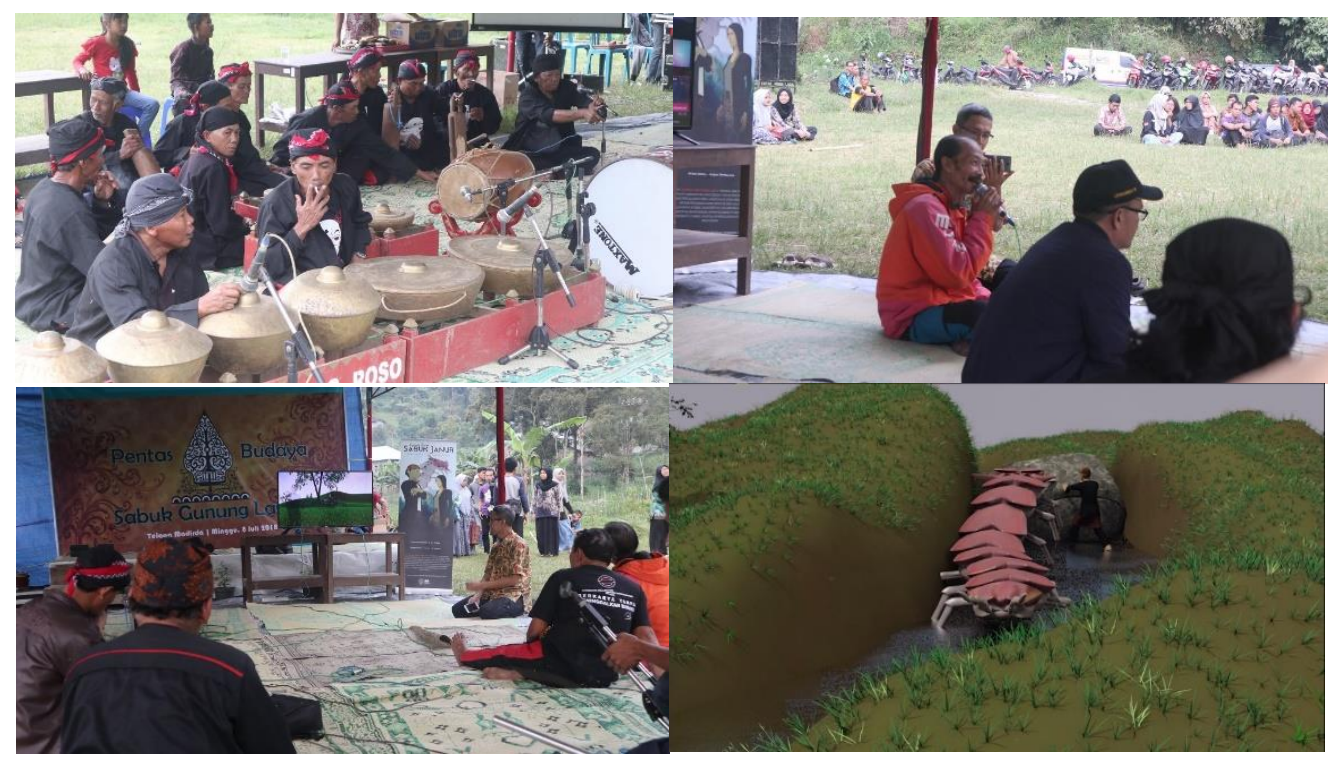

Gambar 4. Pemutaran film Legenda Tarian Sabuk Janur pada masyarakat Karangpandan di Telaga Madirda Karanganyar.

Hasil penilaian masyarakat terhadap film animasi tersebut dilakukan untuk menilai aspek pengetahuan responden tentang cerita Ki Sabuk Janur, pemahaman responden tentang isi cerita Ki Sabuk Janur dan kualitas film 
dari segi modeling, audio, maupun visual efek. Terdapat 11 responden yang menilai film animasi, terdiri dari tokoh budaya, masyarakat setempat dan pakar animasi.

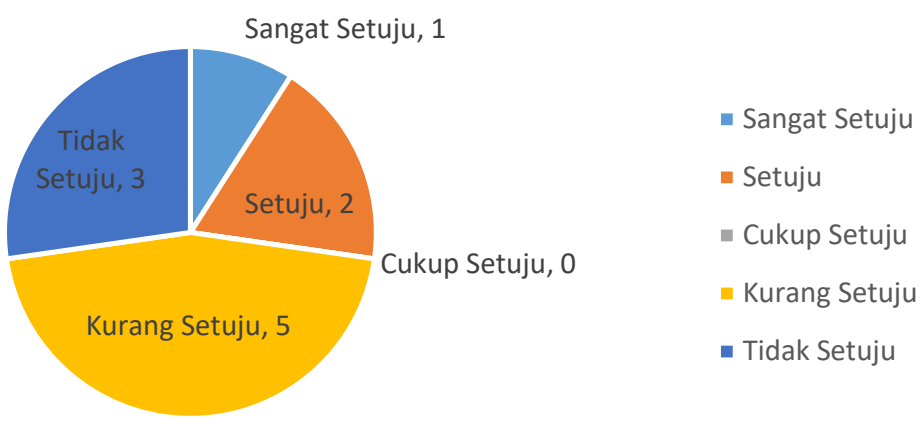

\section{Gambar 5. Grafik pengatahuan masyarakat mengenal cerita Sabuk Janur}

Berdasarkan Gambar 5, persentase responden selama ini dalam mengenal cerita Sabuk Janur sebesar 27\% dan sisanya $73 \%$ masyarakat setempat belum mengenal cerita tersebut.

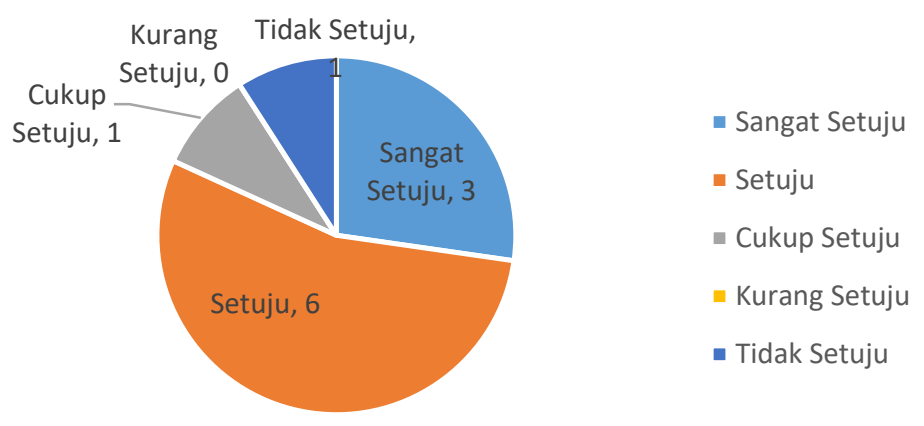

\section{Gambar 6. Grafik pemahaman masyarakat setelah melihat film Sabuk Janur}

Berdasarkan Gambar 6, setelah melihat film animasi yang ditayangkan ternyata masyarakat menjadi tahu tentang cerita Sabuk Janur tersebut sebesar $82 \%$ dan ternyata terjadi di lokasi yang mereka tinggal dan terdapat bukti mengenai aliran air dari Gunung Lawu tersebut. Nilai tersebut menambah pengetahuan masyarakat mengenai cerita legenda khas di daerah tersebut.

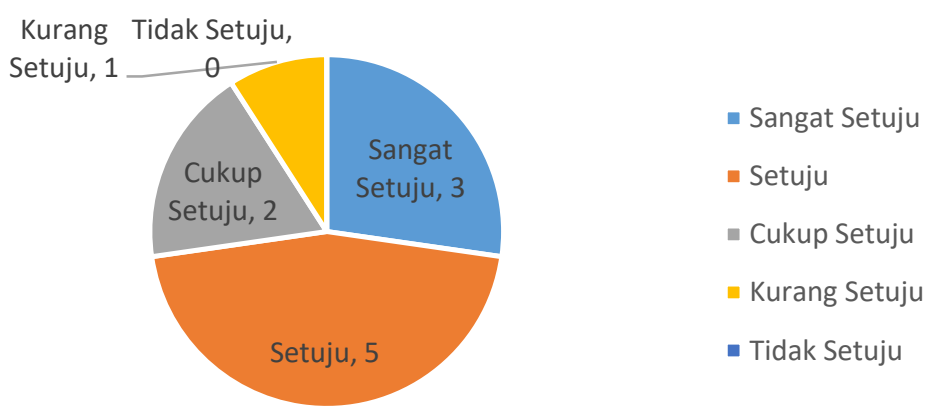

Gambar 7. Grafik kebaikan penyajian model 3D

Berdasarkan Gambar 7, penyajian model 3D meliputi model karakter, lingkungan disajikan dengan baik sebesar $73 \%$ responden menilai baik dan sangat baik. 


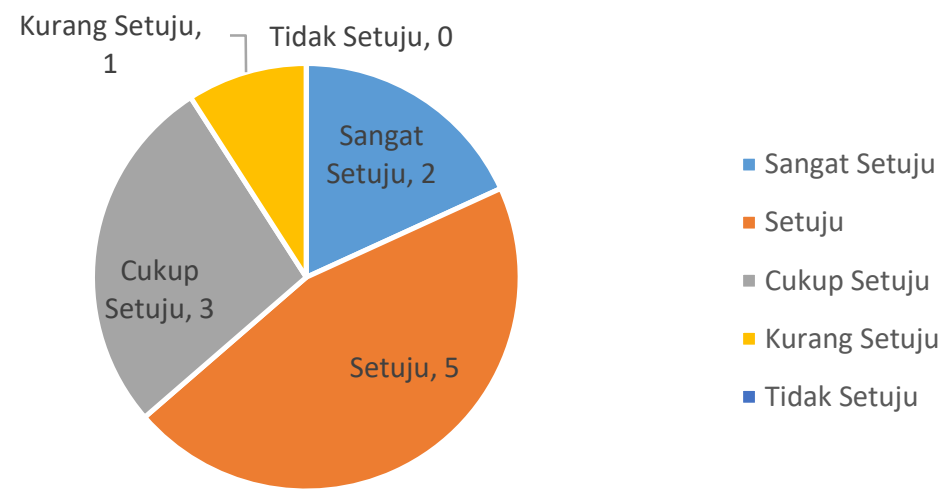

Gambar 8. Grafik kebaikan penyajian visual efek dalam film animasi 3D

Berdasarkan Gambar 8, visual efek yang disajikan dalam film menggunakan software after effect masyarakat menilai baik dan sangat baik sebesar $64 \%$. Visual efek yang diberikan yaitu kemampuan Ki Sabuk Janur dalam melawan Kiongkong dan menyembungkan Kiongkong.

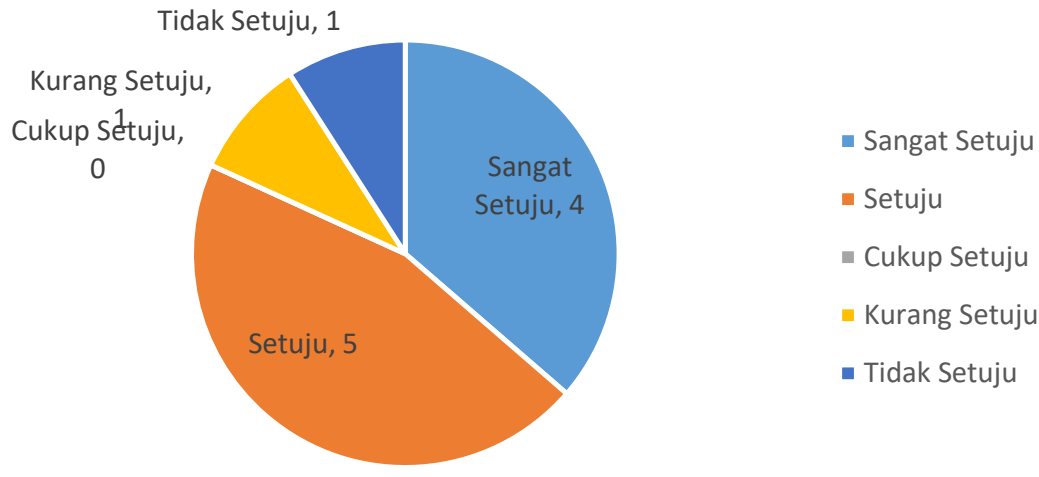

Gambar 9. Grafik kejelasan audio dalam film animasi

Berdasarkan Gambar 9, audio yang terdapat pada film animasi Sabuk Janur masyarakat menilai baik dan sangat baik sebesar $82 \%$. Hal ini menandakan kejelasan informasi disambaikan dengan baik.

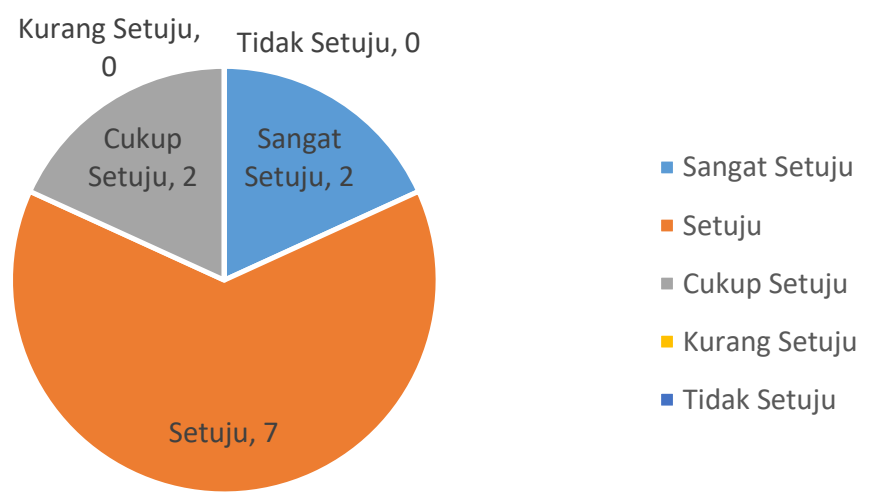

Gambar 10. Grafik kebaikan music latar dalam film animasi 
Berdasar Gambar 10, music latar yang diberikan dalam film animasi Sabuk Janur masyarakat menilai baik dan sangat baik sebesar $82 \%$. Hal ini menandakan bahwa music latar menambah illustrasi suasana film baik saat klimaks maupun jalan cerita yang mudah dipahami.

\section{KESIMPULAN}

Berdasarkan implementasi dan analisa yang telah dibahas sebelumnya dapat disimpulkan bahwa film animasi 3 Dimensi Legenda Tarian Sabuk Janur telah selesai dibuat sehingga dapat diambil beberapa kesimpulan, antara lain: Telah berhasil dibuat film animasi berbasis tiga dimensi dengan judul "Legenda Tarian Sabuk Janur". Cerita "Legenda Tarian Sabuk Janur" dirender dengan spesifikasi ekstensi .mp4, dengan resolusi video $1280 \times 720$. Berdasarkan pengujian melalui kuisioner dapat disimpulkan 82 \% responden dapat memahami isi cerita film animasi 3D Legenda Tarian Sabuk Janur. Dan film disajkan dengan baik rata-rata dengan prosentase sebesar $75 \%$.

\section{DAFTAR PUSTAKA}

[1] A. Yulianjani, A. Martono, D. Apriyani, and P. Production, "Aplikasi Media Interaktif Menggunakan Animasi Cerita Rakyat Untuk Anak Usia Dini ( Studi Kasus Yayasan Bina Insan Kamil Kabupaten Tangerang )," ICIT, vol. 5, no. 1, pp. 77-93, 2019.

[2] F. A. Purnomo, E. H. Pratisto, A. Purnomo, A. S. Huda, A. S. Nugroho, and A. C. Mahendra, "Digital Animasi 2 Dimensi Dengan Metode Cell Shadding Dan Rigging Bone Studi Kasus : Legenda Gunung Tugel," Indones. J. Appl. Informatics, vol. 2, no. 1, pp. 33-46, 2017.

[3] R. Mahendra, A. Trisnadoli, and E. S. Nugroho, "Implementasi Teknik Sinematografi dalam Pembuatan Film Animasi 3D Abstract Cerita Rakyat 'Batu Belah Batu Betangkup,"” Rekayasa Sist. dan Teknol. Inf., vol. 2, no. 2, pp. 578-583, 2018.

[4] Jostonchoniv and Y. Windarto, "Pembuatan Film Animasi 3D Cerita Rakyat ' the Legend of Toba Lake,"' J. Tek. dan IImu Komput., vol. 02, no. 06, pp. 172-179, 2013.

[5] R. V. Toar, B. A. Sugiarso, and V. Tulenan, "Perancangan Short Film Animasi Berbasis 3D Pada Legenda Toar Lumimuut," E-Journal Tek. Elektro dan Komput., vol. 4, no. 5, pp. 1-11, 2015.

[6] J. Nakula and I. N. Semarang, "Pembuatan film animasi 3d 'legenda baru klinting, ," Semarang, 2013. 